\title{
Eficiencia del arbitraje en la garantía del derecho de acceso a la administración de justicia*
}

\author{
Efficiency of Arbitration in Ensuring the Right of Access \\ to the Administration of Justice
}

\author{
Sonia Sánchez Arteaga* \\ Faisury Rodríguez Castillo
}

Fecha de recepción: 5 de mayo del 2020

Fecha de aprobación: 25 de mayo del 2020

\section{RESUMEN}

Este artículo tiene como propósito determinar la relación que existe entre el arbitraje como mecanismo alternativo de solución de conflictos y el derecho de acceso a la justicia. Se observa el arbitraje desde la facultad transitoria otorgada a los particulares en la Constitución de 1991 para administrar justicia. Ello facilita el acceso al arbitraje y su desjudicialización, en el entendido de

Resultado del proyecto de investigación institucional "Alcances del arbitraje en materia de derecho administrativo frente al control de legalidad de los actos administrativos contractuales de la Universidad Libre, seccional de Cali (Colombia).

Citar como: Sánchez Arteaga, S. y Rodríguez Castillo, F. (2020). Eficiencia del arbitraje en la garantía del derecho de acceso a la administración de justicia. Via Inveniendi et Iudicandi, 15(2), 277-297. Dor: https://doi. org/10.15332/19090528/6251

** Abogada por la Universidad del Cauca (Colombia) y psicóloga por la Universidad Nacional Abierta y a Distancia (Colombia); especialista en Derecho de Familia por la Universidad Santiago de Cali; especialista en Docencia Universitaria por la Universidad Cooperativa de Colombia; magíster en Derecho por la Universidad de Manizales; estudiante regular de los cursos válidos para el Doctorado en Derecho de la Universidad de Buenos Aires; coordinadora de la Especialización en Psicología Jurídica y Forense y de la Maestría en Derecho Administrativo de la Universidad Libre. Correo: soniasanchezarteaga@hotmail.com. orcid: https://orcid. org/0000-0002-3443-3862

*** Abogada por la Universidad Libre, seccional de Cali; investigadora externa e integrante del grupo de investigación Derecho Constitucional, Administrativo y Derecho Internacional Público de la Universidad Libre, seccional de Cali. Correo: faroca07@gmail.com. orcid: https://orcid.org/0000-0002-6380-5514 
que el arbitraje cumple una función jurisdiccional y, por tanto, su configuración y procedimiento se enmarcan dentro de la función pública. La justicia arbitral es una manifestación de la efectividad del derecho de acceso a la administración de justicia porque no solo reduce los tiempos de respuesta al conflicto, sino que profiere una decisión que, en el marco del ordenamiento jurídico colombiano, produce los mismos efectos de una sentencia judicial. Esto reafirma este mecanismo como el idóneo para resolver las controversias suscitadas en el marco de la contratación pública.

Palabras clave: derecho fundamental, fines del Estado, función pública, arbitraje, laudo arbitral, acto administrativo, contratación pública.

\begin{abstract}
This article aims to determine the relationship between arbitration as an alternative dispute resolution mechanism and the right of access to justice, seeing this relation in terms of the transitional power to administer justice granted to individuals in the 1991 Constitution. This facilitates access to this right and its de-judicialization, under the supposition that arbitration plays a jurisdictional role and, therefore, its configuration and procedure fall within the public function. Arbitral justice is a manifestation of the effectiveness of the right of access to the administration of justice because it not only reduces response times to conflict, but also renders a decision that, within the framework of the Colombian legal system, produces the same effects as a judicial decision. This reaffirms this mechanism as the appropriate mechanism for resolving disputes arising in the context of public procurement.
\end{abstract}

Keywords: fundamental law, purposes of the State, public service, arbitration, arbitral award, administrative act, public procurement. 
Sonia Sánchez Arteaga, Faisury Rodríguez Castillo

\section{INTRODUCCIÓN}

La función jurisdiccional pertenece principalmente a los jueces y magistrados de la República, ya que el administrar justicia es una facultad exclusiva en cabeza del Estado; sin embargo, a raíz de la demanda social por el efectivo acceso a la administración de justicia, el Estado, a través del legislativo, reconoció y desarrolló normativamente algunos mecanismos con los que compartiría esta función jurisdiccional.

El arbitraje, como mecanismo heterocompositivo para solucionar controversias, ha sido uno de los métodos en los que más se ha avanzado doctrinariamente, de ahí que el Estado haya decidido en el 2012 ambientar el escenario jurídico para la consolidación del arbitraje que no solo impactaría el derecho laboral y mercantil donde ya era aplicado, sino que aportaría significativamente al derecho administrativo. En ese sentido, el arbitraje, al poseer función jurisdiccional, debe velar por la protección y garantía de los derechos de la ciudadanía y de quienes acceden a este para dirimir sus controversias; si bien la fuente principal de protección de derechos se encuentra en las instituciones del Estado, estos mecanismos evidencian la alternatividad del derecho y de las instituciones encargadas de administrar justicia.

En suma, el acceso a la justicia es un derecho constitucional que guarda especial equivalencia con derechos fundamentales constitucionales, como el debido proceso y la igualdad; por ello, es necesario que se haga tutela efectiva de ellos, bien sea a través del sistema judicial o a través de los mecanismos alternativos cuando sea posible hacerlo.

Ahora bien, la introducción del arbitraje en el ordenamiento jurídico colombiano dejó vacíos jurídicos en torno a las situaciones en las cuales opera el arbitramento en el derecho administrativo. Si bien el Estatuto de Arbitraje Nacional, del 2012, contempla algunas situaciones en las que procede este mecanismo, el legislador dejó por fuera un asunto que debió ser complementado por la Corte Constitucional y el Consejo de Estado a través de jurisprudencia. El control de legalidad de los actos administrativos contractuales, a través del arbitraje, ha sido un tema objeto de diversos debates académicos y jurídicos, por lo que la jurisprudencia de estos órganos de cierre ha sido de gran importancia para determinar las situaciones jurídicas que dan lugar al arbitraje como institución que administra justicia. 
Frente a dicha particularidad, cabe destacar que la teoría jurídica considera al juez de lo contencioso administrativo como el juez natural para conocer sobre la legalidad de los actos administrativos, en el entendido de que es este último quien debe garantizar el interés colectivo y los fines esenciales del Estado, entre los que se encuentra la justicia. En coherencia con lo planteado, la garantía desde el arbitraje al derecho de acceso a la administración de justicia en materia administrativa es limitado, debido a varias situaciones. Por una parte, los árbitros no tienen competencia para conocer y decidir sobre diversos asuntos; entre ellos, sobre la legalidad de los actos administrativos. Así lo han detallado distintas sentencias. Por otra parte, el hecho que constituye el arbitraje surge de la voluntad privada, por lo que el acceso a la administración de justicia en el arbitraje depende también de este factor.

No obstante, el legislador, al regular el arbitraje, previó un recurso que permitiera a las personas controvertir y emplear el derecho a la defensa en caso de que no estuviese de acuerdo con la decisión proferida por los árbitros en el laudo. El recurso de anulación es el medio de impugnación contra el laudo arbitral, lo cual no constituye una segunda instancia del arbitraje, puesto que este carece de ella y sus facultades jurisdiccionales son transitorias. Ahora bien, el fundamento jurídico y constitucional de este recurso guarda especial conexión con el derecho al acceso a la administración de justicia y al debido proceso, ya que, al no tener el arbitraje segunda instancia, limita las posibilidades de una decisión efectivamente en derecho; por ello el Estado garantiza a los usuarios del arbitraje acudir a la jurisdicción ordinaria a petición de parte, con la pretensión de resolver la falla producida en el laudo arbitral. Hay que resaltar que la Ley 1563 del 2012 prevé las causales por las cuales se acude a este medio de impugnación, que se sintetizan en tres razones específicas: en la violación de la norma sustancial, en la forma de configuración del arbitraje y en su procedimiento.

\section{GARANTÍA DEL DERECHO AL ACCESO A LA ADMINISTRACIÓN DE JUSTICIA A TRAVÉS DEL ARBITRAJE}

En el Estado social de derecho, el acceso a la justicia es un derecho constitucional que, si bien no se encuentra en los primeros capítulos del texto constitucional, debe ser garantizado efectivamente por el Estado. Con ese propósito y el de equilibrar los poderes 
públicos, existe la rama judicial, que es la encargada de administrar justicia (Gallego, 2014). Este es, entonces, un poder en cabeza exclusiva de las instituciones del Estado; de ahí que en muchos textos y escritos académicos se aluda a él como un monopolio estatal. El acceso a la administración de justicia es, además de un derecho, una función pública, como lo contempla la Carta Política: "La Administración de Justicia es función pública. Sus decisiones son independientes. Las actuaciones serán públicas y permanentes con las excepciones que establezca la ley y en ellas prevalecerá el derecho sustancial" (C. P., 1991, art. 228, Colom.). Con lo anterior se entiende que los funcionarios que se encargan de administrar justicia — en primera medida, los jueces y magistrados — representan el Estado y se encargan de asegurar y garantizar los derechos e intereses de los individuos.

Con relación al acceso a la administración de justicia como derecho constitucional, se encuentra el derecho fundamental al debido proceso (C. P., 1991, art. 29, Colom.), que, entre otras cosas, implica que de manera precedente haya habido una actuación judicial o de tutela jurídica que conlleve a un proceso formal. Así, pues, la garantía al derecho contemplado en el artículo 29 constitucional implicó en primera medida la atención del derecho de acción y la satisfacción del derecho de acceso a la administración de justicia (González, 2016).

El derecho de acceso a la administración de justicia impone al Estado una obligación de naturaleza prestacional, puesto que se trata de un servicio público ofrecido y a cargo del Estado (Sarmiento, Medina y Plazas, 2017), lo que convierte a este último no solo en el principal garante de los derechos de los ciudadanos, sino también en el responsable de las fallas que se puedan cometer tanto en el acceso a la justicia como en las etapas procesales per se. Queda clara así la naturaleza de la justicia como servicio público:

El acceso a la justicia puede analizarse como un problema de un servicio público para el cual existe una demanda y una oferta. Esto, sin que esa perspectiva analítica necesariamente nos conduzca a pensar que se trata de un mercado de la justicia, puesto que estamos hablando de un derecho fundamental. En otras palabras, la protección del derecho de acceso a la justicia requiere la provisión de unos servicios, y para ello, el Estado debe procurar que en un punto se encuentren la demanda y la oferta de estos servicios. (La Rota, S., Santa y Uprimny, 2014, p. 38) 
Quien requiera del acceso a la justicia presenta una pretensión o necesidad jurídica que, a su vez, se traduce en la capacidad de eficacia y de garantías del poder judicial al reconocimiento de derechos que se busquen declarar o que, habiéndolos adquirido, no se hayan satisfecho ni protegido; es decir, la administración de justicia exige del Estado principalmente la capacidad para resolver los conflictos que, en el marco del derecho, se inician a través del derecho de acción. De la gestión que se realice desde el poder judicial también depende la probabilidad de que las personas accedan al sistema judicial o a otras alternativas jurisdiccionales para resolver sus conflictos. El derecho de acceso a la justicia no implica la literalidad de la palabra para demostrar su satisfacción; es decir, no es suficiente con el acceso al sistema judicial para aducir que no se ha vulnerado tal derecho, ya que también implica que, en el marco del proceso, se protejan otros derechos sustanciales; de no ser así, se incurre en el quebrantamiento y vulneración de derechos.

[...] el acceso a la justicia; el proceso, como mecanismo obligado, que constituye el médium en el que ordenadamente se ofrece la respuesta del Estado y en el que se articula la actividad de las partes, y la sentencia, que pone fin al proceso. [...] En este orden de ideas, es importante señalar que la decisión de fondo [...] constituye la respuesta típica del Estado la petición de justicia que se garantiza en el artículo 229 de la CP, dado que de no presuponerse la tutela judicial efectiva perdería todo sentido y utilidad prácticas, como quiera que el acceso no es un fin en sí mismo, sino que apunta a obtener una decisión en derecho. (Muñoz, 1999, pp. 276-277)

Ahora bien, por mandato constitucional todos los individuos pueden acceder a la justicia, siempre que se encuentre en la capacidad para hacerlo; sin embargo, la realidad colombiana evidencia las dificultades de concretar este derecho, ya que en muchos municipios no existe infraestructura ni, mucho menos, jueces que ejerzan la función jurisdiccional. Asimismo, los procesos judiciales suelen ser costosos y usualmente requieren de abogado; de ahí que a la suma de las costas y aranceles judiciales se le agreguen los honorarios del profesional del derecho, situación que complica el acceso a la justicia. Así, las dificultades que se enfrentan no se limitan a lo económico; también hay que decir que la eficacia y efectividad del sistema judicial es otra de ellas, debido a la tardía respuesta para solucionar los conflictos de los ciudadanos. Estos escenarios complejos 
conllevan directamente a la vulneración del derecho al acceso a la justicia elevado a esta categoría por la jurisprudencia y la teoría jurídica: “[...] son derechos fundamentales todos aquellos derechos subjetivos que corresponden universalmente a todos los seres humanos en cuanto dotados del status de personas, de ciudadanos o personas con capacidad de obrar" (Ferrajoli, 2010, p. 37).

La justicia tiene un papel relevante en el Estado social de derecho, ya que este se configura como uno de los pilares constitucionales que configura el Estado. Lo propio ha manifestado la Corte Constitucional de Colombia al reconocer la fundamentalidad de este derecho; de hecho, el no acceso a la administración de justicia vulnera otros derechos fundamentales, como el debido proceso:

De esta forma, el derecho de acceso a la administración de justicia constituye un presupuesto indispensable para la materialización de los demás derechos fundamentales, ya que, como ha señalado esta Corporación "no es posible el cumplimiento de las garantías sustanciales y de las formas procesales establecidas por el legislador sin que se garantice adecuadamente dicho acceso.

(C. C., Sentencia T-799-2011, Colom.)

El carácter de fundamental otorgado al acceso a la administración de justicia implica, entre otras cosas, la obligación del legislador de crear leyes especializadas para este asunto; de ahí que sea la ley estatutaria la encargada constitucionalmente, según el artículo 152, de instituir la organización y operatividad de la administración de justicia porque se la considera un asunto específico y de relevancia para la protección de los derechos fundamentales. En ese sentido, el legislador comprendió que, en el marco de la obligación jurisdiccional que le compete al Estado de garantizar el acceso a la justicia a los ciudadanos del territorio nacional, debía crear mecanismos que contribuyeran a cumplir esta obligación. Ello implicó mitigar el monopolio de la administración de justicia, en el que los jueces y magistrados eran exclusivamente los encargados de solucionar las controversias de las personas.

El Estado tuvo que reconocer y posibilitar jurídicamente mecanismos alternativos de solución de conflictos para garantizar no solamente el acceso a la justicia, sino la eficiencia de los conflictos, por lo que previamente debió aceptar la insuficiencia por parte del 
poder judicial para resolverlos. No quiere decir esto que el poder judicial no contribuya a la solución pacífica de las controversias de los ciudadanos; de hecho, los conflictos jurídicos se tramitan mayoritariamente a través del poder judicial, sino que se parte de que el Estado no tiene la capacidad de garantizar los derechos si es la única institución encargada para tal fin. En ese sentido, el arbitraje se configura como una institución de función jurisdiccional:

[...] el arbitramento se considera como una función pública atribuida a los particulares para administrar justicia, en el contexto de los mecanismos alternativos de solución de conflictos, y que en el del Estado social de derecho, buscan garantizar el derecho de acceso a la justicia en la medida en que contribuyen a la desjudicialización de este, pues trasladan su solución a un escenario diferente del proceso judicial. (Peláez Hernández, 2018, p. 244)

Los mecanismos alternativos de solución de conflictos son instrumentos reconocidos por el Estado para solucionar problemas de carácter jurídico y que sean susceptibles de adelantarse a través de ellos. Podría decirse que, con este reconocimiento, el Estado extiende su poder jurisdiccional a terceros, facultados para tal propósito con la pretensión de que garanticen a los ciudadanos el acceso a la administración de justicia y la protección de los derechos que consideren vulnerados. Estos mecanismos contribuyen, además, a la descongestión de los despachos judiciales; de ahí que esa sea otra de las razones por las que el legislador se haya encargado de regular y especificar los asuntos susceptibles de cada mecanismo.

A través del arbitraje, se garantiza el acceso a la justicia, ya que quien decide sobre un conflicto adelantado mediante este mecanismo es una persona especializada que se encarga exclusivamente de solucionar el conflicto que está a su cargo, a diferencia de los jueces, a quienes constantemente les allegan asuntos de diversa índole, lo que vuelve compleja la eficacia del sistema judicial. A esto se le suma la minúscula cantidad de jueces en el país: según la rama judicial (C. S. Jud. 2010, Colom.), en promedio hay 10 jueces por cada 100000 habitantes, lo que conlleva a que los servicios judiciales tarden más de lo previsto sustancialmente, de ahí que haya sido necesario acudir a alternativas jurídicas que posibilitaran el acceso por parte de los ciudadanos a la administración de justicia. 
La justicia informal también puede permitir una cierta descongestión de los tribunales de controversias que, por sus características, no conviene que reciban un tratamiento judicial. Este alivio de la carga de trabajo de los jueces podría permitir que el aparato judicial se tornara más eficaz para solucionar otros conflictos que sí requieren intervención judicial. El acceso a la administración de justicia, y su credibilidad y legitimidad, deberían verse incrementados, lo cual redunda en beneficio de la democracia y la paz en nuestras sociedades. (Uprimny, 2016, p. 790)

Cabe resaltar que el arbitraje es un mecanismo oneroso. De hecho, muchos de los asuntos que son tramitados bajo esta modalidad versan sobre conflictos de carácter contractual y patrimonial; por ello, no se podría aseverar que este tipo de mecanismos mitiguen las brechas del acceso a la justicia por parte de personas en condiciones vulnerables o de pobreza. Si bien el arbitraje se constituye en un mecanismo alterno al judicial, este debe ser pactado o consensado previamente, lo que implica que debe haber cierto formalismo para su configuración. En el marco de la realidad colombiana, las personas desconocen este tipo de antecedentes convencionales, por lo que podría aducirse que el acceso a la justicia, entendido como la génesis y la conclusión de un proceso formal o informal, se ve afectado por las condiciones económicas y sociales de la desigualdad.

\section{Control de legalidAd de los ACTOS ADMINISTRATIVOS CONTRACTUALES A TRAVÉS DEL ARBITRAJE. UNA MIRADA Desde la JuRisprudencia de la CoRTe Constitucional y EL Consejo de Estado}

El arbitraje, en términos generales, es un procedimiento de carácter jurisdiccional mediante el cual las partes buscan la solución de una controversia mediante la intervención de particulares que han sido investidos de modo transitorio, legal y constitucional para administrar justicia y proferir una decisión que, por ley, se le ha dado la definición de laudo. A dichos particulares se los designa con el calificativo de árbitros, y los efectos jurídicos de dicho laudo resultan equivalentes a los de una sentencia judicial. Ahora, cabe resaltar que el arbitraje, según la ley, también está revestido de unas características que 
han sido delimitadas por la jurisprudencia nacional y que obedecen a factores como la excepcionalidad, la voluntariedad, la temporalidad y la naturaleza procesal.

En materia de derecho administrativo y, específicamente, en lo concerniente a la jurisdicción de lo contencioso administrativo, no ha sido pacífico el desenvolvimiento de la naturaleza procesal del arbitraje, puesto que son diversas las controversias que se han suscitado alrededor de la restricción procesal que la jurisprudencia de las altas cortes (Corte Constitucional de Colombia y Consejo de Estado) ha impuesto, por vía interpretativa, a los tribunales de arbitramento en Colombia, particularmente en los asuntos en los que se discute la legalidad de una actuación estatal. Así, solo en el 2012 se expidió el Estatuto de Arbitraje Nacional e Internacional, que define el arbitraje como: "[...] un mecanismo alternativo de solución de conflictos mediante el cual las partes defieren a árbitros la solución de una controversia relativa a asuntos de libre disposición o aquellos que la ley autorice" (Ley 1563 del 2012, art. 1, Colom.).

Por su parte, la Constitución Política, en su artículo 116, estableció que los particulares podrán ser investidos transitoriamente de la función de administrar justicia en la condición de árbitros habilitados por las partes para proferir fallos en derecho o en equidad en los términos que determine la ley; sin embargo, la referida norma no ha tenido una interpretación consensuada, en la medida en que durante muchos años su aplicación ha estado sujeta a la interpretación restrictiva, en principio, por posturas que han sentado precedente en la materia jurisprudencial. Es el caso de la Sentencia C-1436 del 2000 de la Corte Constitucional, aclarada en años posteriores por medio de Sentencia de Unificación proferida por esa misma entidad en el 2008 y por los diferentes pronunciamientos de la Sección Tercera del Consejo de Estado (por ejemplo, el pronunciamiento del 20 de agosto de 1998, expediente 14202, y el pronunciamiento del 8 de febrero del 2001, expediente 16661), en los que se ha sostenido una tesis principal que se concreta así de modo muy específico:

[...] la jurisdicción contencioso administrativa está instituida, entre otras cosas, para el juzgamiento de la legalidad de los actos de la administración, aspecto este en el cual, sin duda, se encuentra comprometido el ejercicio del poder público, que no resulta transigible ni puede estar sujeto a la voluntad de las partes en un contrato. (C.E., 23 de febrero del 2000, expediente núm. 16394, Colom.) 
A partir de esta tesis reiterativa, se ha entendido jurisprudencialmente que los particulares que asumen la investidura constitucional que los faculta de manera transitoria para administrar justicia, en su calidad de árbitros, no pueden formular ningún pronunciamiento que tenga como fundamento determinar la legalidad de una o varias actuaciones de naturaleza estatal (entiéndase esto como actos administrativos), por cuanto corresponde al Estado, a través de sus jueces, emitir pronunciamientos sobre la forma como sus diversos órganos están desarrollando sus potestades y competencias. Esta postura, en la que se refiere a jueces debidamente competentes, está fundada en artículos de la Constitución Política de Colombia, como el 237, que reza así:

Son atribuciones del Consejo de Estado: 1. Desempeñar las funciones de tribunal supremo de lo contencioso administrativo, conforme a las reglas que señale la ley. [...] 3. Actuar como cuerpo supremo consultivo del Gobierno en asuntos de administración, debiendo ser necesariamente oído en todos aquellos casos que la Constitución y las leyes determinen. (C. P., art. 237, Colom.)

A partir de lo anterior, la postura de la Corte Constitucional y del Consejo de Estado ha versado en reconocer la configuración de los tribunales de arbitramento, en el sentido de la activación de la justicia arbitral en cada caso concreto, ya que es una variable que depende, en gran medida, del acuerdo previo, libre y voluntario de las partes para someter sus controversias a dicho tipo de justicia. Esta premisa se apoya en el hecho de que es la voluntad de las partes en conflicto la que habilita a estos particulares para actuar conforme a las facultades transitorias que la ley y la Constitución nacional les ha otorgado. Pero es la naturaleza procesal la que restringe, según la interpretación de los órganos de cierre mencionados, los alcances de la justicia arbitral en temas muy específicos, tales como la legalidad de actuaciones estatales. A propósito de este panorama, el artículo 1 de la Ley 1563 del 2012, antes mencionada, en su último inciso estableció:

En los tribunales en que intervenga una entidad pública o quien desempeñe funciones administrativas, si las controversias han surgido por causa o con ocasión de la celebración, desarrollo, ejecución, interpretación, terminación y liquidación de contratos estatales, incluyendo las consecuencias económicas de los actos administrativos expedidos en ejercicio de facultades 
excepcionales, el laudo deberá proferirse en derecho. (Ley 1563 del 2012, art. 1, Colom.)

De la lectura del artículo mencionado y según la jurisprudencia en la materia, solo puede formularse una interpretación literal y taxativa cuando se alude al carácter exceptivo que establece la última proposición de dicho artículo. Se concluye de manera inequívoca que el laudo arbitral siempre deberá proferirse en derecho cuando en el tribunal de arbitraje intervenga una autoridad pública o quien desempeñe funciones administrativas, con ocasión de que el conflicto haya surgido de diversos aspectos del contrato estatal, incluidas las consecuencias económicas de los actos administrativos expedidos en virtud de las facultades excepcionales. Por ende, es una clara excepción a la regla general en la que se establece que el laudo arbitral podría ser también en equidad o de naturaleza técnica, y esa excepción obedece a la presencia de una entidad estatal en calidad de parte. La Corte Constitucional, en un pronunciamiento relativamente reciente, estableció al respecto: "Finalmente, el carácter procesal del arbitraje tiene que ver con la sujeción del mecanismo a las reglas previas en la Constitución y la ley, en particular las garantías que integran la cláusula del debido proceso" (C. C., Sentencia C-538-2016, Colom.).

Es precisamente en virtud de las reglas previstas en la Constitución como las Cortes han establecido que dicha excepción, planteada en el artículo 1 de la Ley 1563, debe entenderse como fundamento suficiente para restringir la competencia de los tribunales arbitrales respecto del pronunciamiento de fondo de la legalidad de los actos administrativos expedidos en ejercicio de facultades propias de cada entidad estatal. $Y$ es así porque la mención de esos actos administrativos es uno de los varios aspectos que trae la norma para describir la participación de la entidad estatal, lo que lleva a concluir que el laudo debe proferirse en derecho, pero no establece ninguna limitación respecto a la competencia de los árbitros.

A partir de este razonamiento, la jurisprudencia ha establecido que el acto administrativo, como expresión inequívoca de la voluntad de la administración, tiene una tendencia normal y natural a producir efectos jurídicos, y dichos efectos pueden derivarse de la creación, modificación y extinción de situaciones jurídicas para los administrados o en contra de estos; en tal sentido, el acto administrativo en sí mismo tendría como presupuestos básicos la sujeción al orden jurídico y el respeto por los derechos y garantías que le asisten a los administrados: 


\begin{abstract}
Todos aquellos asuntos relativos a la competencia de la jurisdicción contenciosa administrativa para confrontary decidir sobre la legalidad de actos administrativos relacionados con los contratos estatales, incluso los que se producen en los contratos estatales con la calidad subsidiaria de una solución principal que no se pudo obtener de acuerdo con lo preceptuado por el artículo 61 de la Ley 80 de 1993, no son susceptibles de pronunciamiento alguno por parte de la Justicia Arbitral [...] el hecho que tales actos se dicten en desarrollo de un contrato, no les da una fisonomía propia, porque el contrato no es la fuente de la cual dimana el poder para expedirlos, sino que esa fuente radica únicamente en la ley. (C. C., Sentencia SU-174-2007, Colom.)
\end{abstract}

En tal sentido, y frente a la clara restricción de la competencia de los árbitros respecto a la legalidad de los actos administrativos de carácter excepcional, queda claro que las medidas adoptadas por la administración estatal, concretadas en los contratos de naturaleza administrativa, solo pueden ser objeto de examen por parte de la jurisdicción contenciosa administrativa. Así lo instauraron pronunciamientos como el del Consejo de Estado del 2000 (Expediente núm. 16973) y otro de la misma corporación del siguiente año (Expediente núm. 19090). Ambos coinciden en que, si bien los particulares investidos temporalmente de la facultad de administrar justicia tienen características propias que se desarrollan en virtud de la ley que las reglamenta, existen implicaciones de diferente índole - especialmente económica - de las que se deriva de modo casi obligatorio el riguroso ejercicio de establecer la legalidad de un acto administrativo que reglamente una relación contractual.

Es precisamente en virtud de tal ejercicio como se ha establecido que debe ser la jurisdicción de lo contencioso administrativo la que determine la legalidad de dichos actos administrativos. Por tanto, es evidente que la jurisprudencia ha establecido reglas claras respecto de la decantación de este tipo de asuntos, que son de competencia exclusiva de los jueces de tal naturaleza y, por ende, indelegable en los particulares que obran como árbitros. Esto se da porque la determinación que se adopta en este tipo de actuaciones es de naturaleza estrictamente estatal, de manera que son únicamente los jueces quienes deben establecer si dichas actuaciones se ajustan al marco legal constitucional correspondiente y en función de la prevalencia del interés público y el cumplimiento de los fines esenciales del Estado social de derecho en Colombia. 
La competencia de los árbitros está limitada no solo por el carácter temporal de su actuación sino por la naturaleza del asunto sometido a su conocimiento, pues solo aquellas materias susceptibles de transacción pueden ser definidas por los árbitros. Los particulares investidos de la facultad de administrar justicia no pueden pronunciarse sobre asuntos que involucren el orden público, la soberanía nacional o el orden constitucional, asuntos que, en razón de su naturaleza, están reservados al Estado, a través de sus distintos órganos. (C. C., Sentencia C-1436-2000, Colom.)

De este análisis, solo resta decir que no se puede asignar a los particulares la facultad de pronunciarse respecto de aquellas cuestiones que implican un examen de las funciones estatales — como la emisión de actos administrativos y su legalidad—, puesto que dicha atribución, según las Cortes en sus diferentes pronunciamientos, es exclusiva de los jueces. En cuanto a la competencia que se les reserva a los árbitros, queda claro que en el laudo arbitral sus facultades quedan supeditadas a discusiones de carácter patrimonial que se desprendan de la constitución o configuración de un acto administrativo, mas no podrán pronunciarse respecto de cualquier aspecto que signifique la revisión de la legalidad de dichos actos. Se refiere esto a aspectos como los de la caducidad de un contrato estatal, su modificación o terminación o cualquier otra hipótesis jurídica que gire en torno a esta naturaleza, pues no se puede olvidar que el Estado actúa en defensa del interés general y que, precisamente porque son actuaciones de orden público, no pueden ser objeto de disponibilidad, sino que, en caso de que surja alguna controversia, esta deberá decantarse por medio de la jurisdicción contencioso administrativa. Como se sabe, según la instrucción constitucional y la jurisprudencia desarrollada, es el juez natural respecto de la legalidad que atañe a un acto de la administración pública.

\section{El LAUDO ARBITRAL Y SUS ALCANCES JURÍDICOS}

El arbitraje, como mecanismo de heterocomposición de solución de controversias, posee importantes beneficios para quienes de manera voluntaria y consensuada acceden a él. De ahí que sea de especial interés profundizar en este artículo sobre los alcances jurídicos del laudo arbitral, especialmente en materia de derecho administrativo. Ahora bien, a diferencia del sistema judicial en el que los jueces o magistrados se pronuncian a través 
de autos y sentencias, en el arbitraje los terceros imparciales encargados de solucionar la controversia específica lo hacen a través de laudos arbitrales. Este mecanismo reconocido por el Estado posee efectos avalados por él mismo; en ese sentido, el Estado debió desarrollar un marco normativo para la aplicación y ejecución del arbitraje en la sociedad colombiana; de ahí que la Ley 1563 del 2012 lo defina de la siguiente manera: "El laudo arbitral es la sentencia que profiere el tribunal de arbitraje" (art. 1, Colom.). Ahora, es pertinente recalcar la importancia del laudo, no solo porque pone fin a un conflicto, sino porque los árbitros que toman la decisión son personas con suficiente pericia en el asunto en cuestión; de ahí que, en la elaboración del laudo, los árbitros hayan deliberado y argumentado sus posturas y, por tanto, la decisión amerita la participación activa de los árbitros en todo el procedimiento:

El fallo debe ser promulgado por un tribunal arbitral, es decir compuesto por árbitros, quienes se escogen en función de profundos y de mostrados conocimientos sobre una materia en particular. Dicho laudo debe contener no solo la solución que las partes deberán acoger, sino los fundamentos de esta y tiene como efecto su tránsito a cosa juzgada. (Fernández, 2018, p. 168)

El laudo arbitral y sus efectos jurídicos presentan una característica que pone en ventaja el arbitraje sobre otros mecanismos alternativos, como la amigable composición. Podría decirse que, gracias a esto, también es uno de los mecanismos más desarrollados normativamente, al igual que la conciliación. En principio, una de las teorías que dieron génesis al arbitraje, la teoría contractualista, no reconoce los efectos jurídicos del arbitraje, debido a que no estiman que su carácter contractual tenga efectos de carácter jurisdiccional; sin embargo, tanto la ley como la jurisprudencia en Colombia han avanzado en determinar los alcances de estos dos mecanismos. Es claro que la conciliación presta mérito ejecutivo y hace tránsito a cosa juzgada. Así se ha manifestado en diversos textos normativos, a diferencia del arbitraje que, debido a su tardía regulación, fue el Consejo de Estado y la Corte Constitucional de Colombia los que le otorgaron jurisprudencialmente los mismos efectos.

El laudo o decisión arbitral es de obligado cumplimiento para las partes y produce efectos idénticos a la cosa juzgada (art. 37 LA). De ese modo el laudo, 
además de decidir con carácter definitivo las cuestiones objeto de controversia, no puede ser revisado en vía jurisdiccional salvo motivos tasados y específicos, pudiendo obtenerse su ejecución forzosa por los trámites establecidos para la ejecución de sentencias. (Trayter, 1997, p. 81)

El Estado, al reconocer el efecto de cosa juzgada a los laudos arbitrales, posibilita un segundo efecto, el de mérito ejecutivo, con la finalidad de que esta decisión sea exigible posteriormente en caso de incumplimiento; sin embargo, en tal caso, los árbitros que deciden sobre el asunto carecen de fuerza jurídica para exigir el cumplimiento del laudo, debido a que esta es una facultad que pertenece exclusivamente al monopolio de la justicia, en cabeza del Estado, y, además, porque el árbitro cesa en su calidad de administrador de justicia una vez esté proferido y en firme el laudo arbitral. Esta es una de las principales razones para desconocer parcialmente el carácter jurisdiccional del arbitraje, porque bien podría decirse que administrar justicia solo implica el periodo procesal en el que se resuelve la controversia, pero lo cierto es que tener esa calidad pública implica poseer la potestad requerida para hacer cumplir lo decidido, sin necesidad de acudir a la jurisdicción ordinaria o a la vía judicial, situación que no es posible ni en el arbitraje ni en otro mecanismo alternativo de solución de conflictos.

En el arbitraje no procede la segunda instancia, puesto que es un tribunal investido transitoriamente para administrar justicia; sin embargo, en caso de contradicción de las partes con la decisión tomada en el laudo, debe garantizarse el derecho a la defensa. De ahí que el legislador haya comprendido la necesidad de un recurso pertinente que permita controvertir judicialmente la decisión de los árbitros; además, porque la interposición de este recurso garantiza el debido proceso, derecho constitucional que fundamenta el acceso a la administración de justicia.

Ahora bien, hay que precisar que el recurso que pretenda anular el laudo arbitral debe ceñirse a unos parámetros legales —entiéndanse los límites establecidos de manera taxativa en las causales estipuladas en la ley_-, precisamente en virtud de la protección del debido proceso como derecho de rango constitucional. En sentido estricto, las decisiones emitidas por el tribunal de arbitramento no gozan de un mecanismo de impugnación, y ello, en consecuencia, de la garantía del principio de autonomía de la voluntad que les asiste a las partes que deciden decantar o dirimir sus controversias por medio de justicia 
impartida por particulares investidos por la ley para ello. En todo caso, el ordenamiento jurídico colombiano ha previsto un escenario procesal en el cual se puede someter un laudo arbitral al discernimiento de un operador jurídico de la jurisdicción ordinaria, siempre que se limite a la revisión de ciertos aspectos relacionados con irregularidades procesales que no hayan sido observadas ni subsanadas en el trámite arbitral.

En este orden de ideas, vale realizar aclaraciones al respecto. De entrada, no puede considerarse la anulación de un laudo arbitral como una actuación de procedimiento jurisdiccional asimilable a una instancia ordinaria, en la que la construcción jurídica por parte del juez y el ejercicio probatorio tienen unas implicaciones muy diferentes a la de un laudo arbitral:

[...] al juez de anulación le está vedado examinar, modificar o replantear el fondo de la decisión arbitral y, por consiguiente, su fundamentación fáctica, probatoria y normativa, precisamente por carecer de jurisdicción y competencia a propósito de la materia controvertida. [...] el recurso de anulación no es una segunda instancia y, por tanto, está circunscrito a la materia expresamente consagrada en la ley, sin comprender la definición jurídica, hermenéutica de los preceptos y valoración probatoria resuelta en el laudo arbitral, en torno de las cuales, carece el juzgador de absoluta jurisdicción, al sustraerse de su juzgamiento y asignarse a los árbitros por el pacto arbitral. (C. C., SU 173-2015, Colom.)

De esta manera, en lo que concierne a controversias dirimidas por tribunal de arbitramento en las que esté involucrada como parte una entidad del Estado, deberá entenderse que el Consejo de Estado, en lo ateniente a su función judicial de revisión del laudo arbitral, no podrá cuestionar la interpretación formulada por los árbitros inmersos en la decisión del laudo, como tampoco efectuar una nueva valoración probatoria; de lo contrario, se estaría configurando un desbordamiento del margen de competencia conferida por el ordenamiento jurídico al juez natural de este tipo de asuntos (Quiroz, 2014). Por tanto, y como deducción de lo anterior, el recurso de anulación respecto de laudos arbitrales no puede entenderse como una segunda instancia que se surte solo en virtud de un proceso ordinario, que, para el caso en el que se encuentren intereses del Estado, aplicaría a la jurisdicción de lo contencioso administrativo, sino que se trata de un mecanismo instituido con el objetivo procedimental de examinar el pronunciamiento arbitral por 
errores en el procedimiento, en los que hipotéticamente hubiesen incurrido los árbitros del tribunal en cuestión, mas no por errores en la manera de juzgar, salvo que el interesado del recurso de anulación alegue una causal que comporte tal valoración.

Un ejemplo de este panorama jurídico puede encontrarse en pronunciamiento del Consejo de Estado del 2018. En dicho asunto, la convocada interpuso recurso de anulación en contra de laudo del 20 de octubre del 2017, proferido por tribunal arbitral constituido para dirimir las diferencias originadas en razón del Convenio de Operación de los Servicios de Telemedicina, celebrado el 1 de abril del 2010, entre la Federación Colombiana de Municipios y la Unión Temporal Cardiplus Telemedicina Colombia, Saludcoop eps (en liquidación), Cruz Blanca ePs y Cafesalud EPs S.A. En este, las convocantes afirmaron que la convocada (la Federación Colombiana de Municipios) incumplió el convenio, pues "no prestó ninguno de los servicios de telemedicina contratados, no hizo entrega de los equipos necesarios para la operación de dichos servicios ni reintegró el dinero pagado por las contratantes a título de anticipo una vez terminado el contrato" (C.E., Recurso de anulación de laudo arbitral 2018, Colom.)

En tal sentido, el Consejo de Estado anuló el laudo arbitral proferido el 20 de octubre del 2017, toda vez que el numeral 2. ${ }^{\circ}$ del artículo 41 de la Ley 1563 del 2012 prevé la caducidad del medio de control como causal de anulación del laudo, y dicho presupuesto de derecho se logró probar dentro de esta instancia de revisión, que se agotó a petición del recurrente. Este mismo hizo valer los motivos constitutivos de la caducidad mediante recurso de reposición contra el auto de asunción de competencia; por tanto, este pronunciamiento es un ejemplo claro de una anulación de laudo arbitral en virtud de un requisito de procedibilidad que no se agotó en la decisión inmersa en el laudo arbitral.

Queda claro entonces que el recurso extraordinario de anulación no podría ser interpuesto con el ánimo de que se surta con las características y presupuestos propios de una segunda instancia, en la que se pretenda darle continuidad o replantear el debate sobre el fondo del asunto sujeto a litigio, puesto que la decisión del recurso de anulación no implica, como ya se dijo, el estudio de los razonamientos formulados por los árbitros del tribunal ni, mucho menos, sobre la aplicación que se dé de la ley sustancial o la valoración realizada por los árbitros respecto de la materia probatoria puesta a disposición. 
Sonia Sánchez Arteaga, Faisury Rodríguez Castillo

\section{ConClusión}

De conformidad con lo expuesto en este artículo, podría decirse que el arbitraje es un mecanismo que, por su naturaleza y reconocimiento constitucional, garantiza el acceso a la administración de justicia, entre otras razones, por los efectos jurídicos que emanan del laudo arbitral y porque el Estado, en aras de garantizar este derecho, ha previsto un medio de impugnación que permita a las personas controvertir judicialmente la decisión proferida del tribunal arbitral. Ello constituye el arbitraje como mecanismo integral que ofrece las garantías necesarias para el acceso a la justicia, entendido este no solo como el ingreso a la jurisdicción, sino también como el debido proceso y el respeto a las normas procesales y sustanciales. De igual manera, en este artículo se pretendió exponer brevemente algunas las posturas de la Corte Constitucional y el Consejo de Estado sobre la materia, específicamente sobre la legalidad de los actos administrativos de carácter contractual, debido a que, si bien existe una ley que regula el arbitraje en el ordenamiento jurídico colombiano, esta contiene algunos vacíos jurídicos que son determinantes para la comprensión y funcionamiento de la justicia arbitral; de ahí que hayan sido estos órganos de cierre judicial los encargados de complementar jurisprudencialmente la norma jurídica y de establecer sus alcances y limitaciones.

\section{REFERENCIAS}

Colombia. Ley 1563 del 2012. Por medio de la cual se expide el Estatuto de Arbitraje Nacional e Internacional y se dictan otras disposiciones. D. O. núm. 48.489.

Consejo de Estado [C. E.], 2000, C.P.: Germán Rodríguez Villamizar, Expediente núm. 16.394. Actor: Consorcio Hispano-alemán.

Consejo de Estado [C.E.], 2000, C.P.: Alier E. Hernández Enríquez, Expediente núm. 16.973, actor: Consorcio Amaya-Salazar.

Consejo de Estado [C.E.], 2001, C.P.: María Elena Giraldo Gómez, Expediente núm. 19.090, actor: Instituto de Desarrollo Urbano.

Consejo de Estado [C. E.], 2018, Sala de lo Contencioso Administrativo, Sección Tercera, Subsección C, C.P.: Guillermo Sánchez Luque. Actor: Saludcoop EPS en liquidación 
y otros. Demandado: Federación colombiana de Municipios. Recurso de anulación de lado arbitral, [Colom.].

Consejo Superior de la Judicatura [C. S. J.], 2010, Boletín Estadístico, Sala Administrativa. Plan Sectorial de Desarrollo, [Colom.].

Constitución Política de Colombia [C.P.], 1991. [31. a ed., 2013], Gómez Sierra, F. (editor y comentarista). Bogotá: Leyer.

Corte Constitucional de Colombia [C.C.], 2000, M.P.: Alfredo Beltrán Sierra, Sentencia C- 1436, Demanda de inconstitucionalidad en contra de los artículos 70 y 71 de la Ley 80 de 1993, [Colom.].

Corte Constitucional de Colombia [C. C.], 2007, M. P.: Manuel José Cepeda Espinosa, Sentencia de unificación 174, [Colom.].

Corte Constitucional de Colombia [C. C], 2011, M. P.: Humberto Antonio Sierra Porto, Sentencia T-799, [Colom.].

Corte Constitucional de Colombia [C. C.], 2015, M. P.: Gabriel Eduardo Mendoza Martelo, Sentencia de Unificación 173, [Colom.].

Corte Constitucional de Colombia [C. C.], 2016, M. P.: Luis Ernesto Vargas Silva, Sentencia C-538, [Colom.].

Fernández, V. (2018). Arbitrabilidad de los actos administrativos contractuales. Bogotá: Instituto Latinoamericano de Altos Estudios (ILAE).

Ferrajoli, L. (2010). Derechos y garantías: la ley del más débil. Madrid: Trotta.

Gallego, J. (2014). Paradoja y complejidad de los derechos humanos en la sociedad moderna: sentido y comunicación. IUSTA, (40), 143-165.

González, O. (2016). La omisión legislativa como hecho generador de la responsabilidad patrimonial del Estado. Verba Iuris, 11(35), 41-63. Recuperado de https://revistas.unilibre. edu.co/index.php/verbaiuris/article/view/5/2

La Rota, M., S., L., Santa, S. y Uprimny, R. (2014). Ante la justicia: necesidades jurídicas y acceso a la justicia en Colombia. Bogotá: Centro de Estudios de Derecho, Justicia y Sociedad- Dejusticia. 
Muñoz, E. C. (1999). Acceso a la justicia y debido proceso en Colombia: síntesis de la doctrina constitucional. Anuario Iberoamericano de Justicia Constitucional, (3), 271-3108.

Peláez Hernández, R. A. (2018). Arbitramento y derecho de acceso a la justicia: aspectos procesales. En O. Woolcott-Oyague, D. F. Monje-Mayorca, G. Comandé, R. A. Peláez Hernández y A. Alarcón-Peña (Eds.), Estudios contemporáneos de derecho privado: responsabilidad civil, propiedad, contratos y obligaciones (pp. 241-279). Bogotá: Universidad Católica de Colombia.

Quiroz, M. (2014). Acercamiento a las “oposiciones paradigmáticas” entre neoconstitucionalismo y positivismo jurídico. IUSTA, 41(2), 77-97.

Sarmiento, D., Medina, S. y Plazas, R. (2017). Sobre la responsabilidad y su relación con el daño y los perjuicios. Via Inveniendi et Iudicandi, 12(2), 101-115. https://doi.org/ https://doi.org/10.15332/s1909-0528.2017.0002.05

Trayter, J. M. (1997). El arbitraje de derecho administrativo. Revista de Administración Pública, (143), 75-106. Recuperado de https://dialnet.unirioja.es/descarga/articulo/17354.pdf

Uprimny, R. (2016). Los riesgos y las potencialidades de la justicia informal. En M. García Villegas y M. A. Ceballos Bedoya (Eds.), Democracia, justicia y sociedad: diez años de investigación en Dejusticia (pp. 786-796). Bogotá: Centro de Estudios de Derecho, Justicia y Sociedad (Dejusticia). 